\title{
Les aliments au soja : consommation en France, qualités nutritionnelles et données scientifiques récentes sur la santé
}

\author{
Dominique Chevalier, Christine Debeuf, Gwénaële Joubrel ${ }^{\star}$, Martine Kocken et Nadine Planchenault \\ SOJAXA : Association Française des Fabricants d'Aliments au Soja, 11, rue de Monceau, 75008 Paris, France
}

Reçu le 6 avril 2016 - Accepté le 25 mai 2016

\begin{abstract}
Résumé - Aujourd'hui, 4 Français sur 10 consomment des aliments au soja. Les consommateurs les ont intégrés dans leur alimentation, sans bouleverser leurs habitudes alimentaires, parce qu'ils les considèrent naturels et sains. Les non consommateurs sont en attente de plus d'informations (origine géographique du soja et qualités nutritionnelles). La consommation est assez récente et devrait progresser dans les prochaines années. Les aliments élaborés à partir de la graine de soja fournissent des protéines de très bonne qualité nutritionnelle, des acides gras insaturés, des fibres, des vitamines et des minéraux. La graine de soja contient des isoflavones, dont une grande partie est éliminée lors de l'élaboration des aliments au soja (qui en contiennent 1 à $3 \mathrm{mg} / \mathrm{g}$ de protéine). La consommation actuelle d'aliments au soja est largement compatible avec l'apport maximal de $1 \mathrm{mg} / \mathrm{kg} / \mathrm{j}$ recommandé par l'Afssa en 2005. Le développement infantile avec les préparations à base de protéines de soja est comparable à celui observé avec celles à base de protéines de lait de vache ou avec le lait maternel, sur tous les paramètres étudiés (croissance, santé osseuse et fonctions métaboliques, reproductives, endocrines, immunitaires et neurologiques). Les aliments au soja semblent exercer un effet protecteur vis-à-vis du risque de cancer du sein (probablement lié aux isoflavones), surtout si la consommation est débutée avant l'adolescence. Chez les femmes ayant des antécédents de cancer du sein, l'alimentation peut intégrer les aliments au soja. Introduire des aliments à base de soja dans l'alimentation contribue aussi à maintenir la santé cardiovasculaire, du fait de leur effet favorable sur le taux de LDL-cholestérol, sur la fonction endothéliale, et potentiellement sur la tension artérielle.
\end{abstract}

Mots clés : Alimentation / soja / consommation / nutrition / santé

\begin{abstract}
Soyfoods: consumption in France, nutritional qualities and recent scientific data on its contribution to health. Today, 4 French people out of 10 eat soyfoods. Consumers have adopted them in their diet, without changing their habits, because they consider them natural and healthy. The non-users are waiting for more information (geographical origin, nutritional benefits). The consumption is relatively new and is expected to grow in the coming years. Soyfoods produced from soybeans provide high quality proteins, unsaturated fatty acids, fibres, vitamins and minerals. Soybeans contain isoflavones, much of which is lost during the production of soyfoods, which contain between 1 and $3 \mathrm{mg}$ per g protein. The current consumption of soyfoods is largely consistent with the maximum intake of $1 \mathrm{mg} / \mathrm{kg}$ /day recommended by the Afssa in 2005. Infant development with formulas based on soy protein is similar to that observed with those based on cow milk or with breast milk, on all studied parameters (growth, bone health and metabolic, reproductive, endocrine, immune and neurological functions). Soyfoods may have a protective effect against the risk for breast cancer (probably due to isoflavones), particularly if the consumption starts early, before adolescence. In women with breast cancer history, soyfoods can be integrated in the diet. Introduce soyfoods in the diet also helps to maintain cardiovascular health, because of their favorable effect on LDL-cholesterol, endothelial function and potentially on blood pressure.
\end{abstract}

Keywords: Food / soya / consumption / nutrition / health

^ Correspondance : g.joubrel@sojaxa.com 


\section{Introduction}

La Sojaxa est l'association professionnelle regroupant les principaux fabricants d'aliments au soja en France. Une de ses missions est d'informer sur les produits au soja, leurs caractéristiques nutritionnelles et leurs impacts sur la santé et l'environnement.

Les adhérents de la Sojaxa s'engagent notamment à utiliser du soja provenant majoritairement de France, garanti sans OGM, et à produire leurs aliments à partir de la graine de soja.

Malgré une consommation historique dans certains pays, notamment asiatiques, le soja et les aliments élaborés à partir de la graine de soja restent peu connus des Français et font encore l'objet d'idées reçues. C'est pourquoi la Sojaxa a lancé récemment une enquête afin de mieux connaître la perception des aliments au soja par les Français et leurs comportements de consommation.

Lorsqu'ils sont élaborés à partir de la graine de soja, les aliments au soja présentent des qualités nutritionnelles tout à fait intéressantes, qui sont rappelées dans cet article et justifient leur intégration au sein d'une alimentation destinée au maintien de la santé.

Les aliments au soja contiennent également des isoflavones, dont l'activité faiblement oestrogénique a suscité de nombreux débats quant à leurs effets favorables ou défavorables sur la santé au cours des dernières décennies. Mais les études les plus récentes apportent un éclairage rassurant sur la relation entre le soja et la santé, c'est donc dans un climat apaisé que les aliments au soja peuvent aujourd'hui trouver leur place au sein d'une alimentation diversifiée, apportant leur contribution à l'équilibre alimentaire et à la santé.

\section{Le soja en France : perceptions et comportements de consommation}

Afin de mieux connaître les perceptions et comportements des Français vis-à-vis du soja, la Sojaxa a lancé une enquête, en décembre 2014, réalisée par l'institut d'études QualiQuanti auprès d'un échantillon représentatif de la population française (1140 répondants, Fig. 1), grâce à un questionnaire en ligne de 70 questions. L'étude s'est intéressée à différents paramètres : l'image du soja et des produits au soja, les comportements d'achat, le profil des consommateurs et les usages culinaires (Sojaxa, 2005). Cette étude sera reconduite tous les 2 ans afin de suivre les évolutions dans le temps.

Les principaux résultats de cette première étude sont les suivants :

- La consommation d'aliments au soja se démocratise : plus de 4 Français sur 10 (41\% des répondants) sont consommateurs d'aliments au soja en 2014 : $19 \%$ ont consommé 1 ou 2 catégories d'aliments au soja, $10 \%$ ont consommé 3 ou 4 catégories de produits et $12 \%$ ont consommé 5 catégories de produits ou plus (Fig. 2).

- La consommation d'aliments au soja est relativement récente : près d' 1 consommateur sur 2 en consomme depuis moins de 5 ans, $13 \%$ d'entre eux les consomment d'ailleurs depuis moins d'un an.
- Les produits au soja sont consommés plutôt par les femmes, et plutôt par des plus de 40 ans (Fig. 3). La consommation des produits au soja est un phénomène plutôt urbain avec une majorité des consommateurs résidant dans les grandes villes et en région parisienne.

- Les consommateurs réguliers (qui consomment un produit au soja au moins une fois par mois) représentent $27 \%$ de la population. Les produits au soja s'intègrent de plus en plus dans les habitudes alimentaires des consommateurs : deux tiers d'entre eux en achètent au moins une fois par mois et $30 \%$ des consommateurs en achètent au moins une fois par semaine.

- Les consommateurs ne limitent pas leur consommation à un seul produit au soja. Ils achètent en moyenne 3,8 types de produits au soja différents. Les différentes catégories d'aliments au soja sont achetées par les consommateurs (Fig. 4) :

- Les produits consommés les plus fréquemment sont les spécialités fermentées ( yaourt » au soja aromatisé ou aux fruits et «yaourt» au soja nature, Fig. 4) : au moins 1 fois par semaine pour $59 \%$ des consommateurs, suivis des boissons au soja (55 \%) et des desserts de type crème (47\%).

- Les aliments au soja n'ont pas créé un nouveau registre culinaire, ils sont intégrés aux habitudes alimentaires et permettent de diversifier l'alimentation et de revisiter des recettes usuelles : les boissons au soja sont utilisées dans les pâtisseries, les aides culinaires alternent avec la crème dans de nombreuses recettes et les steaks ou galettes de soja sont poêlés, assaisonnés et servis accompagnés de légumes. Ils sont ainsi particulièrement consommés en guise de plat (pour $79 \%$ des consommateurs) et de dessert (pour $63 \%$ des consommateurs) lors des deux principaux repas de la journée que sont le déjeuner et le dîner.

- La consommation de produits au soja devrait augmenter dans les prochaines années : en effet, si $48 \%$ des consommateurs pensent maintenir leur consommation de soja au même niveau, $34 \%$ des consommateurs actuels pensent consommer plus de produits au soja dans les deux prochaines années.

- Concernant les non consommateurs, $37 \%$ déclarent ne pas acheter d'aliments au soja parce qu'ils n'y pensent pas (ils ne font pas partie de leurs habitudes d'achat). Deux tiers d'entre eux déclarent attendre plus d'information sur le soja : l'origine, les modes de production, les différents produits et leurs usages, leurs bénéfices environnementaux et nutritionnels, ...

- Un des freins à la consommation concerne l'origine géographique du soja et la présence d'OGM : alors que les aliments proposés par les adhérents de la Sojaxa sont garantis sans OGM et que $98 \%$ des graines sont cultivées en France, seulement $14 \%$ des répondants sont convaincus de l'absence d'OGM dans les produits. Et plus de $30 \%$ des répondants pensent que la culture du soja se fait principalement à l'étranger.

- Les autres freins à la consommation portent sur le goût perçu par les non consommateurs (un aliment qui ne fait pas envie pour $47 \%$ d'entre eux), et sur l'utilisation (un produit auquel on ne pense pas pour $37 \%$ ou qu' on ne sait pas cuisiner pour $23 \%$ ). 


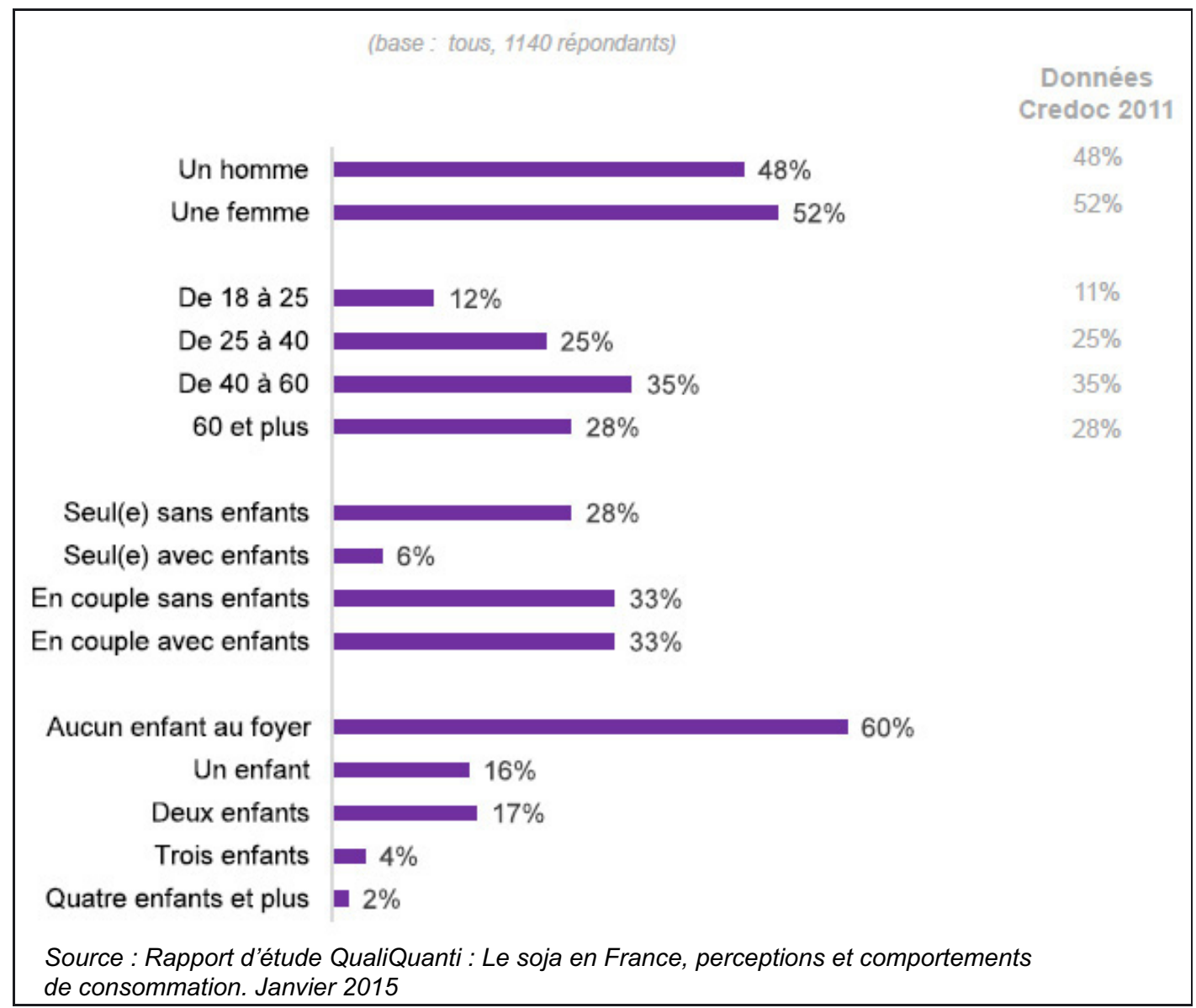

Fig. 1. Composition de l'échantillon ayant répondu à l'étude.

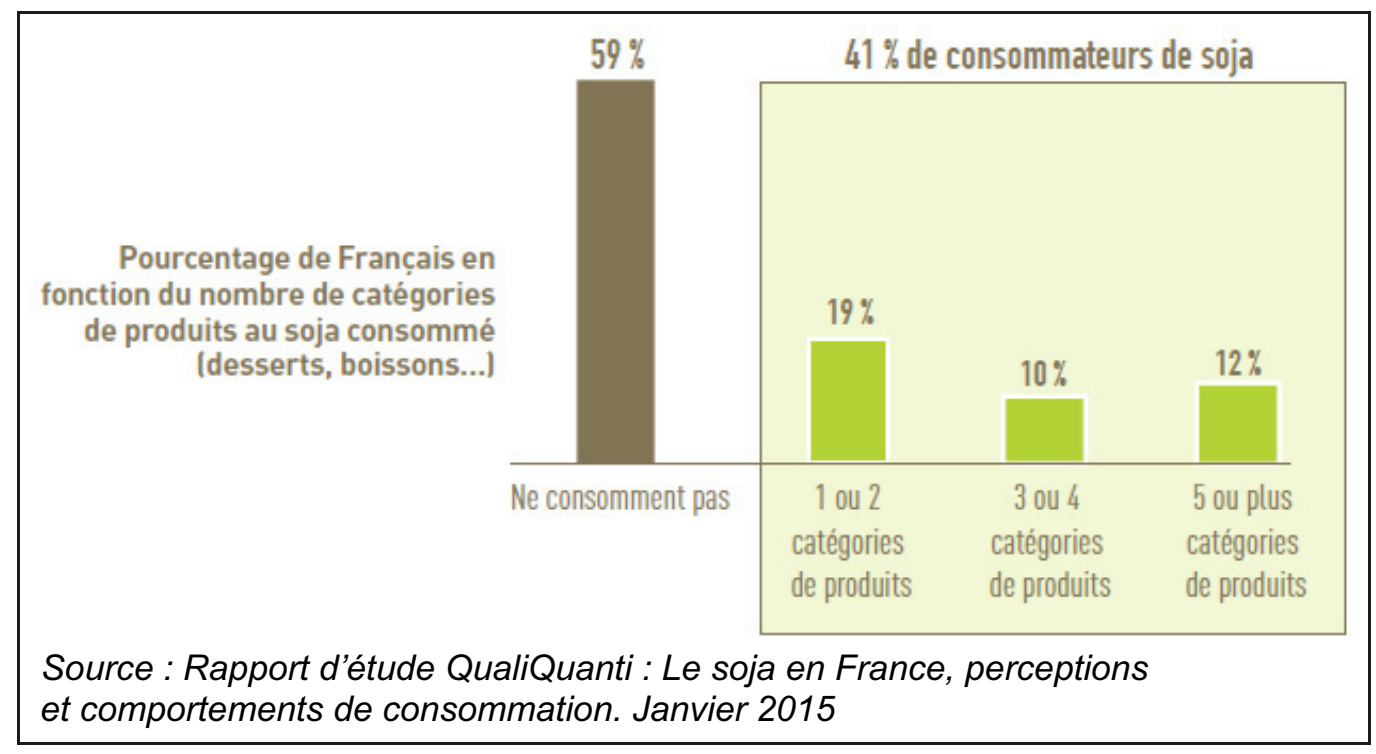

Fig. 2. Consommation d'aliments au soja en France en 2014. 


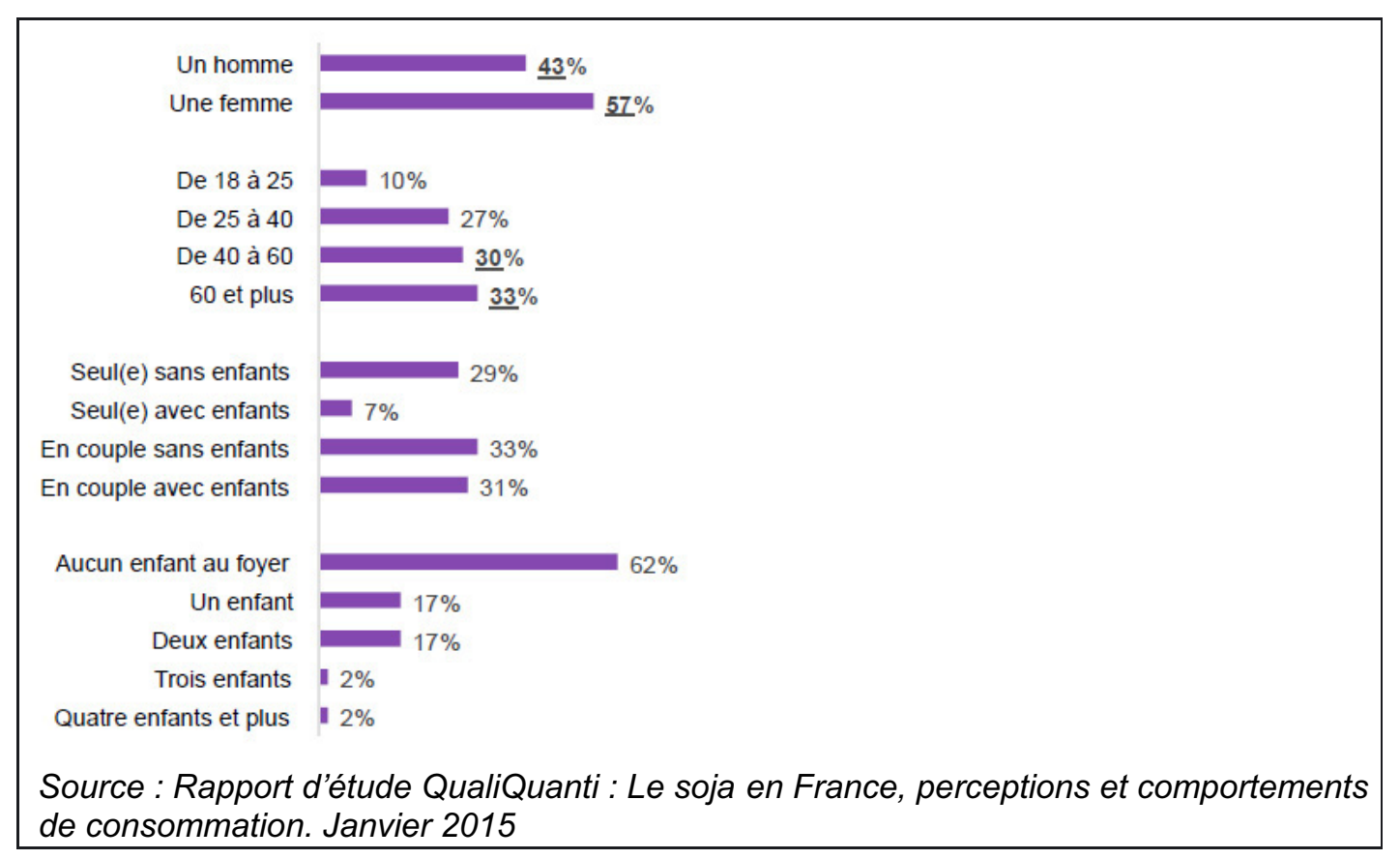

Fig. 3. Profil des consommateurs d'aliments au soja.

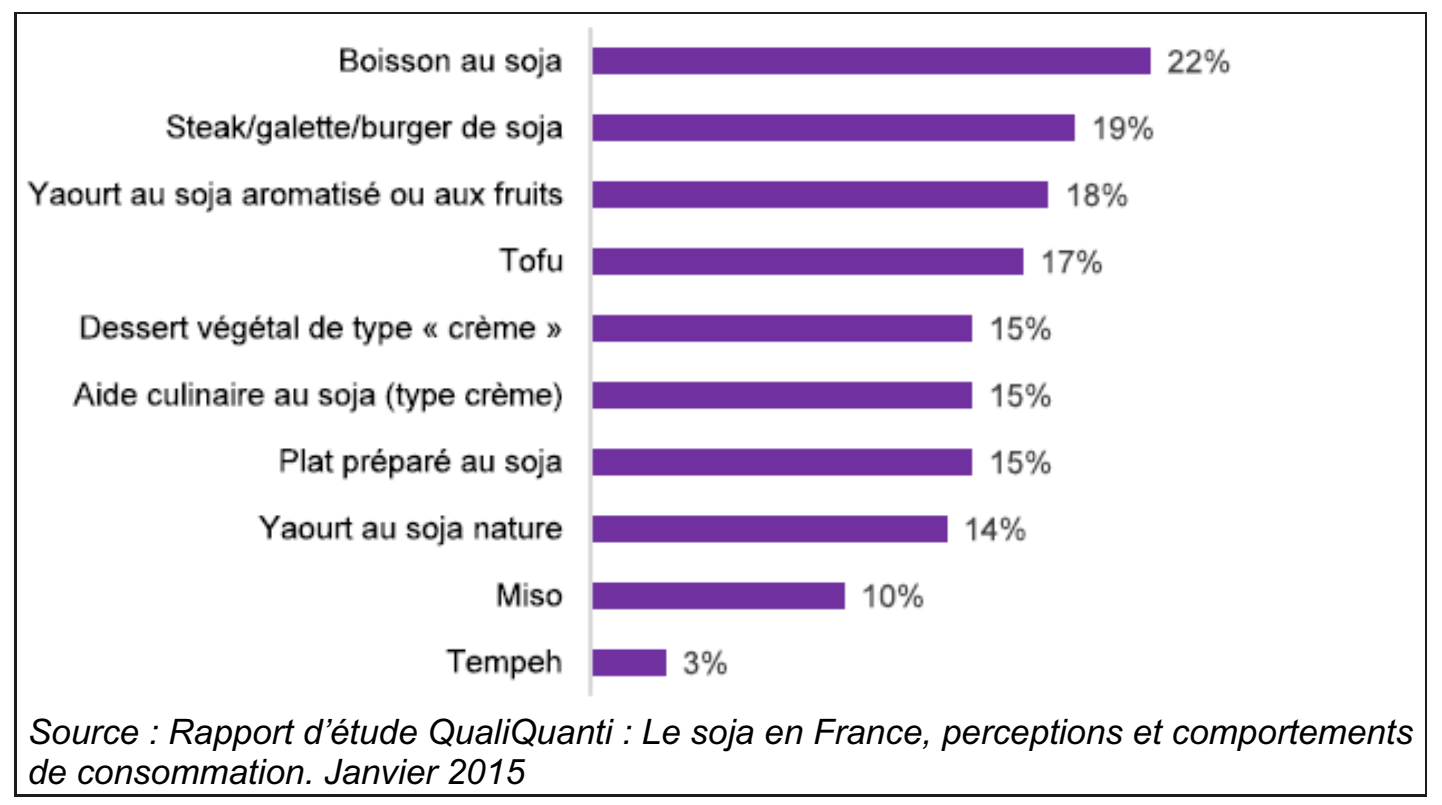

Fig. 4. Détail des produits au soja consommés au cours des 12 derniers mois.

- Les atouts environnementaux du soja sont encore méconnus des Français, puisque seulement $53 \%$ des répondants ont l'image d'un aliment respectueux de l'environnement.

- $66 \%$ des non consommateurs ont une image neutre des aliments au soja, tandis que $71 \%$ des consommateurs perçoivent les aliments au soja comme naturels et sains, s'intégrant dans une alimentation équilibrée. Les principales raisons de consommation des produits au soja sont illustrées par la Figure 5.
Les données les plus récentes relatives à la consommation d'aliments au soja en France sont les suivantes (source : Kantar, mars 2016) :

- 17,4 \% des foyers français ont acheté au moins une fois dans l'année des produits au soja. Le volume d'achat moyen est de 8,5 kg par an, ce qui représente environ $163 \mathrm{~g}$ par semaine et par foyer.

Les consommateurs les plus réguliers ( 1 consommateur de soja sur 5 , soit moins de $5 \%$ des foyers français) achètent $32 \mathrm{~kg}$ 


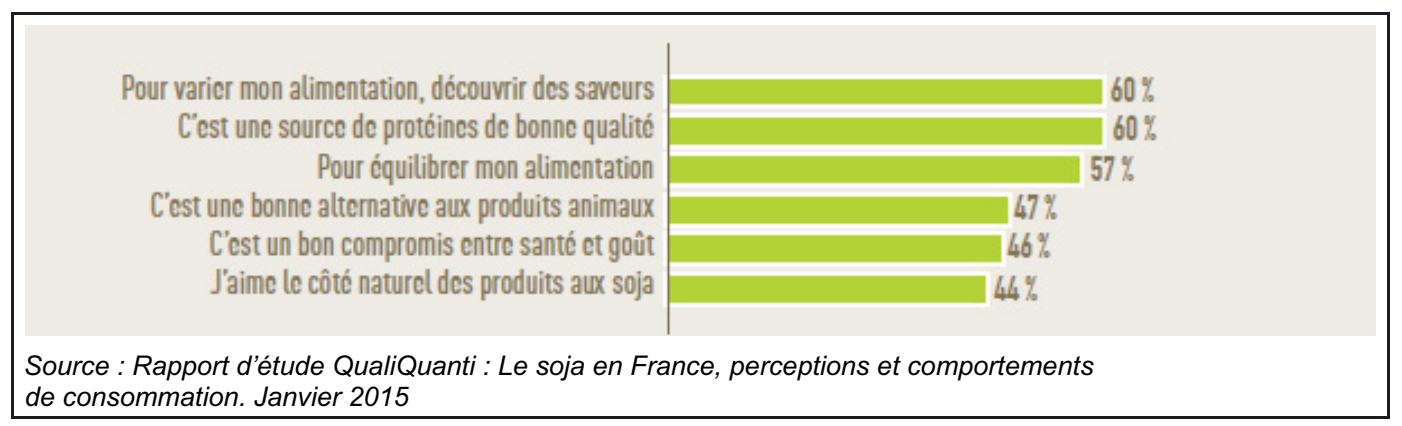

Fig. 5. Principales raisons de consommation des produits au soja (pour les consommateurs.

d'aliments au soja par an, ce qui représente environ $615 \mathrm{~g}$ par semaine et moins de $90 \mathrm{~g}$ par jour.

Les qualités nutritionnelles et les atouts des aliments au soja pour la santé font partie des facteurs qui motivent leur consommation. Le chapitre suivant s'attache à présenter le profil nutritionnel de la graine de soja et des aliments et boissons élaborés à partir de la graine.

\section{Qualités nutritionnelles du soja et des aliments au soja}

\subsection{La graine de soja}

Le soja (Glycina max) est une plante annuelle de la famille des légumineuses (pois, haricot...). On confond souvent les graines de soja avec celles du haricot mungo (Vigna radiata), que l'on trouve dans le commerce par exemple sous forme de « germes de soja » appertisés, utilisés notamment dans les salades composées.

D'origine asiatique, où le soja est utilisé dans l'alimentation humaine depuis plus de trois millénaires sous forme de produits traditionnels (tonyu, tofu), la culture du soja s'est développée en Amérique (États Unis, Brésil, Argentine...) et plus récemment en Europe. La France en produit surtout dans le sud-ouest, 260000 tonnes pour la récolte 2015, dont $20 \%$ sont utilisés pour produire des aliments destinés à l'alimentation humaine (le reste étant destiné à l'alimentation animale).

Son intérêt réside dans sa richesse exceptionnelle en protéines et lipides. C'est en effet l'une des graines la plus riche en protéines du monde végétal (Fig. 6).

Du fait de la présence en quantité relativement élevée des 9 acides aminés essentiels, et d'une digestibilité satisfaisante (de $90 \%$ en moyenne par rapport aux protéines de référence : WHO, 2007), les protéines de soja sont pratiquement les seules du monde végétal à pouvoir se comparer aux protéines animales. Leur indice chimique correspond à $120 \%$ de celui de la protéine de référence $\mathrm{WHO}$; il est un peu inférieur à celui des protéines animales (blanc d'œuf et lait de vache), du fait d'un taux plus bas en acides aminés soufrés (Tab. 1). L'association des protéines de soja à celles des céréales (déficitaires en lysine) permet un apport en acides aminés tout à fait satisfaisant.

Le score PDCAAS (protein digestibility corrected amino acid score) de la protéine de soja se situe entre 0,9 et 1,0 selon la nature des aliments au soja (Hughes et al., 2011;

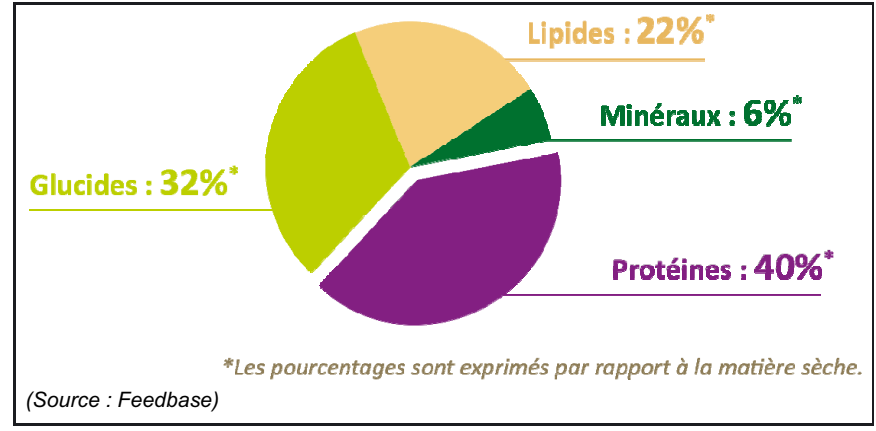

Fig. 6. Composition nutritionnelle de la graine de soja.

Rutherfurd et al., 2015). De petites différences de PDCAAS entre les aliments au soja sont attribuables à des différences mineures au niveau du profil en acides aminés et de la digestibilité, résultant de différences de procédés de fabrication et de teneurs différentes en fibres et ou en phytates (Gilani, 2005).

Récemment, la FAO (Food and Agriculture Organization of the United Nations) a recommandé d'adopter un nouveau score pour évaluer la qualité des protéines, le DIAAS (digestible indispensable amino acid score) (FAO, 2013). Le DIAAS de la protéine de soja est un peu inférieur au PDCAAS, puisque c'est la digestibilité iléale d'acides aminés individuels qui est utilisée pour évaluer la digestibilité selon le DIAAS, au lieu de la digestibilité fécale de la protéine totale selon le PDCAAS, mais la protéine de soja conserve un DIAAS de l'ordre de 0,9 , qui est bien supérieur au score de 0,75 recommandé par la FAO comme critère pour les allégations nutritionnelles relatives aux protéines de haute qualité (FAO, 2013).

Par ailleurs, la graine de soja apporte des lipides (22\%), caractérisés tout d'abord par l'absence de cholestérol (comme tous les végétaux), un faible apport en acides gras saturés (15\% des acides gras totaux), une majorité d'acides gras insaturés $(85 \%$ des acides gras totaux, dont $7 \%$ d'acides gras poly-insaturés oméga-3), le tout protégé par la présence de la vitamine $\mathrm{E}$ (environ $0,9 \mathrm{mg} / 100 \mathrm{~g}$ ).

Enfin, la graine de soja est une source de fibres : $10 \mathrm{~g}$ pour $100 \mathrm{~g}$ de graine de soja cuite selon la base de données américaine (USDA, 2015) et apporte des quantités intéressantes de minéraux (en particulier potassium : $515 \mathrm{mg} / 100 \mathrm{~g}$ et fer : $5,4 \mathrm{mg} / 100 \mathrm{~g}$ ) et de vitamines (du groupe B et vitamine E). 
Tableau 1. Indice chimique de protéines alimentaires.

\begin{tabular}{|c|c|c|c|c|c|c|}
\hline $\begin{array}{c}\text { AA en } g \text { pour } \\
100 \mathrm{~g} \text { de protéines }\end{array}$ & $\begin{array}{l}\text { Protéines de soja } \\
\text { (Santé Canada) }\end{array}$ & $\begin{array}{c}\text { Protéine de référence } \\
\text { (WHO, 2007) }\end{array}$ & $\begin{array}{l}\text { Blanc d'œuf } \\
\text { (WHO, 1985) }\end{array}$ & $\begin{array}{l}\text { Lait de vache } \\
\text { (WHO, 1985) }\end{array}$ & $\begin{array}{c}\text { Blé } \\
\text { (Santé Canada) }\end{array}$ & $\begin{array}{c}\text { Riz blanc } \\
\text { (Santé Canada) }\end{array}$ \\
\hline Histidine & 2,6 & 1,5 & 2,2 & 2,7 & 2,3 & 2,3 \\
\hline Isoleucine & 4,6 & 3,0 & 5,4 & 4,7 & 3,3 & 4,3 \\
\hline Leucine & 7,7 & 5,9 & 8,6 & 9,5 & 6,5 & 8,3 \\
\hline Lysine & 6,3 & 4,5 & 7,0 & 7,8 & 3,1 & 3,6 \\
\hline Méthionine+ Cystéine & 2,8 & 2,2 & 5,7 & 3,3 & 2,7 & 4,4 \\
\hline Phénylalanine + Tyrosine & 8,5 & 3,8 & 9,3 & 10,2 & 8,6 & 8,7 \\
\hline Thréonine & 4,1 & 2,3 & 4,7 & 4,4 & 2,7 & 3,6 \\
\hline Tryptophane & 1,4 & 0,6 & 1,7 & 1,4 & 1,3 & 1,2 \\
\hline Valine & 4,7 & 3,9 & 6,6 & 6,4 & 3,9 & 6,1 \\
\hline Indice chimique & $120 \%$ & $100 \%$ & $146 \%$ & $150 \%$ & $69 \%$ (lysine) & $80 \%$ (lysine) \\
\hline
\end{tabular}

Source Santé Canada : Fichier canadien sur les éléments nutritifs : www.hc-sc.gc.ca.

Tableau 2. Composition nutritionnelle de boissons et desserts élaborés à partir de graines entières de soja (données SOJAXA). Enrichissement volontaire ponctuel* ou très fréquent**, précisé dans l'étiquetage nutritionnel des produits concernés.

\begin{tabular}{lcccc}
\hline $\begin{array}{l}\text { Valeurs nutritionnelles } \\
\text { pour } 100 \mathrm{~g} / \mathrm{ml}\end{array}$ & $\begin{array}{c}\text { Dessert au soja, } \\
\text { saveur vanille }\end{array}$ & $\begin{array}{c}\text { Dessert fermenté } \\
\text { au soja et aux fruits }\end{array}$ & $\begin{array}{c}\text { Dessert fermenté } \\
\text { au soja, nature }\end{array}$ & $\begin{array}{c}\text { Boisson au soja nature, } \\
\text { plus calcium }\end{array}$ \\
\hline Energie $(\mathrm{kJ})$ & 375 & 337 & 230 & 189 \\
$\quad(\mathrm{kcal})$ & 89 & 80 & 55 & 45 \\
Matières grasses $(\mathrm{g})$ & 1,8 & 2,2 & 2,7 & 2,0 \\
dont acides gras saturés $(\mathrm{g})$ & 0,3 & 0,4 & 0,5 & 0,3 \\
Glucides $(\mathrm{g})$ & 14,7 & 10,8 & 2,4 & 3,0 \\
dont sucres $(\mathrm{g})$ & 10,4 & 9,7 & 2,2 & 2,6 \\
Protéines $(\mathrm{g})$ & 3,1 & 3,7 & 4,7 & 3,6 \\
Fibres $(\mathrm{g})$ & 0,8 & 0,6 & 0,4 & 0,6 \\
Sel $(\mathrm{g})$ & 0,15 & 0,1 & 0,1 & 0,1 \\
Calcium $(\mathrm{mg})^{* *}$ & $120^{* *}$ & $120^{* *}$ & $120^{* *}$ & $120^{* *}$ \\
Vitamine D $(\mu \mathrm{g})^{*}$ & - & $1,2^{*}$ & - & $0,75-1,0^{*}$ \\
\hline
\end{tabular}

\subsection{Les aliments au soja}

La propriété première des aliments et boissons au soja, et l'une des raisons historiques de leur consommation en France, est l'absence de lactose et de protéines de lait, permettant leur consommation chez des personnes présentant une intolérance à ce sucre ou une allergie aux protéines de lait de vache. Ces caractéristiques expliquent le développement initial de boissons et de desserts fermentés ou de desserts de type crème à base de soja. À l'origine, ces produits se présentaient donc comme des alternatives aux produits laitiers.

De plus, du fait de leur origine végétale, ces boissons et aliments au soja n'apportent pas de cholestérol, et présentent un profil en acides gras tout à fait intéressant : peu d'acides gras saturés, une majorité d'acides gras insaturés et un apport significatif en acides gras poly-insaturés. Ces caractéristiques expliquent la seconde raison historique du développement des aliments et boissons au soja sur le marché français : ils ont également été recommandés aux personnes souffrant de troubles du métabolisme lipidique, en particulier d'hypercholestérolémie.

Aujourd'hui, au-delà de toute problématique de santé, et du fait même de leurs caractéristiques nutritionnelles, ces produits sont consommés par des personnes en bonne santé qui cherchent à équilibrer leur alimentation, notamment à augmenter leur consommation en protéines végétales, souvent minori- taires dans notre alimentation, ou à diminuer leur consommation d'acides gras saturés et de cholestérol (Tabs. 2-4).

Les desserts et boissons au soja présentent un profil en acides gras intéressants, du fait de l'absence de cholestérol, de la faible teneur en acides gras saturés (inférieure ou égale à $0.5 \%$ dans les desserts et boissons). Des préparations de type «crème » ont également été développées : elles servent d'aide culinaire et s'utilisent comme une crème fluide légère, avec les atouts nutritionnels du soja : absence de cholestérol, faible apport d'acides gras saturés, richesse en acides gras polyinsaturés, notamment en acide alpha-linolénique (oméga-3).

Les produits issus du soja comme le tofu, les galettes ou les steaks de soja sont, quant à eux, riches en protéines de soja. En alternance avec les sources de protéines animales, ils permettent de satisfaire les apports recommandés en protéines, tout en limitant l'apport lipidique (rapport protéines/lipides $\geqslant$ à 1), et en apportant des quantités significatives de fibres alimentaires, dont les apports sont généralement inférieurs à $20 \mathrm{~g} /$ jour dans notre alimentation, alors que les recommandations sont de $25 \mathrm{~g} /$ jour pour les adultes (EFSA, 2010).

Par ailleurs, de nombreux produits, parmi les différentes gammes disponibles sur le marché, sont enrichis en calcium, à des teneurs équivalentes à celles des produits laitiers correspondants. La biodisponibilité du calcium présent dans les aliments au soja est satisfaisante (Heaney, 1991; Tang, 2010; Zhao, 2005). 
Tableau 3. Composition nutritionnelle de tofu et plats cuisinés élaborés à partir de graines entières de soja (données SOJAXA).

\begin{tabular}{lcc}
\hline $\begin{array}{l}\text { Étiquetage nutritionnel } \\
\text { pour } 100 \mathrm{~g}\end{array}$ & Tofu nature & $\begin{array}{c}\text { Croques, filet, nuggets, panés, } \\
\text { steaks de soja (natures) }\end{array}$ \\
\hline Énergie (kJ) & 615 & 727 \\
$\quad(\mathrm{kcal})$ & 148 & 174 \\
Matières grasses $(\mathrm{g})$ & 9,3 & 8,9 \\
dont acides gras saturés $(\mathrm{g})$ & 1,5 & 1,1 \\
Glucides $(\mathrm{g})$ & 1,1 & 6,8 \\
dont sucres $(\mathrm{g})$ & 0,8 & 2,4 \\
Protéines $(\mathrm{g})$ & 14,4 & 16,7 \\
Fibres $(\mathrm{g})$ & 1,6 & 6,5 \\
Sel $(\mathrm{g})$ & 0,3 & 1,5 \\
\hline
\end{tabular}

Tableau 4. Composition nutritionnelle moyenne des aides culinaires élaborées à partir de graines entières de soja (données SOJAXA).

\begin{tabular}{lc}
\hline $\begin{array}{l}\text { Etiquetage nutritionnel } \\
\text { pour } 100 \mathrm{~g}\end{array}$ & $\begin{array}{c}\text { Aides culinaires } \\
\text { à base de soja }\end{array}$ \\
\hline Energie $(\mathrm{kJ})$ & 662 \\
\multicolumn{1}{c}{$(\mathrm{kcal})$} & 159 \\
Matières grasses $(\mathrm{g})$ dont & 15,0 \\
acides gras saturés $(\mathrm{g})$ & 2,2 \\
Glucides $(\mathrm{g})$ & 3,2 \\
dont sucres $(\mathrm{g})$ & 1,8 \\
Protéines $(\mathrm{g})$ & 3,1 \\
Fibres $(\mathrm{g})$ & 0,6 \\
Sel $(\mathrm{g})$ & \\
\hline
\end{tabular}

C'est l'ensemble de ces caractéristiques nutritionnelles qui font des aliments et boissons élaborés à partir de graines entières de soja des composants importants de l'équilibre alimentaire. L'Afssa, dans son rapport sur les phyto-estrogènes (2005), a d'ailleurs reconnu l'intérêt nutritionnel de consommer 1 à 2 aliments au soja par jour pour une alimentation équilibrée.

Le chapitre suivant est consacré aux isoflavones du soja, ces polyphénols également qualifiés de phyto-oestrogènes du soja.

\subsection{Les isoflavones du soja}

Comme tous les autres végétaux alimentaires, le soja contient naturellement des polyphénols. Parmi les polyphénols recensés à ce jour, on connaît plus de 4000 variétés de flavonoïdes, dont font partie les isoflavones, présentes surtout dans le soja, mais aussi dans d'autres légumineuses (pois chiches, lentilles).

Les isoflavones ont une structure chimique proche de celle des oestrogènes, ce qui leur permet de se fixer faiblement aux récepteurs aux oestrogènes (ER $\alpha$ et $\mathrm{ER} \beta$ ) (Kuiper, 1997; 1998). Pour cette raison, elles sont capables d'exercer de faibles effets oestrogéniques dans certaines conditions expérimentales, et sont qualifiées de «phyto-oestrogènes ».

Outre les isoflavones, les lignanes et les coumestanes sont également qualifiés de phyto-oestrogènes. On trouve les lignanes dans de très nombreuses céréales, fruits, légumes (céleris, asperges, courges, brocolis, ...) mais aussi dans le vin, le thé. Le lin est la source majoritaire des lignanes. Parmi les coumestanes, le coumestrol est le plus oestrogénique. Il est présent dans la plupart des légumes, en quantités infimes. On en trouve par exemple dans les choux de Bruxelles. Enfin, les stilbènes, dont le resvératrol, présent dans le vin rouge et le raisin, ont également une activité oestrogénique (COT, 2003).

Les deux principales isoflavones sont la daïdzéine et la génistéine, la glycitéine étant présente en quantité mineure dans la graine de soja et localisée principalement au niveau du germe. Ces molécules existent sous quatre formes : aglycones (daïdzéine et génistéine), glycosylées (daïdzine et génistine), glycosylées acétylées et glycosylées malonylées.

Dans son rapport de 2005, 1'Afssa avait cherché à évaluer la sécurité des phyto-estrogènes. Force lui avait été de constater qu'il existe peu d'études de toxicité portant sur les différents types de phyto-estrogènes. Parmi les études disponibles, beaucoup portent sur l'une des isoflavones du soja : la génistéine. Ces études ont permis d'établir une NOAEL, c'est-à-dire la dose limite sans effet adverse, à $120 \mathrm{mg}$ par kg de poids corporel et par jour. Une telle dose, rapportée à une personne de $70 \mathrm{~kg}$, reviendrait à consommer $8400 \mathrm{mg}$ d'isoflavones/jour.

La plupart des études disponibles ont été menées chez le rat. Or, l'Afssa soulevait la question de la pertinence de ce modèle pour l'étude des phyto-estrogènes, dans la mesure où le rat est capable de produire de l'équol en grande quantité, à partir de la daïdzéine. Pour être actives sur le plan physiologique, les isoflavones doivent être sous la forme aglycone, seule forme absorbée au niveau intestinal. Dans la graine de soja et les produits non fermentés dérivés de ces graines (boissons, tofu), les isoflavones sont sous forme glycosylée, donc inactives. Lorsqu'elles sont ingérées, les isoflavones glycosylées sont partiellement converties en isoflavones aglycones par la flore intestinale. Il existe une très grande variabilité interet intra-individuelle de la biodisponibilité des isoflavones, car tout facteur modifiant la flore intestinale perturbe ses capacités à convertir les isoflavones en forme aglycone : composants du régime (fibres), antibiotiques, ... Les isoflavones aglycones sont ensuite métabolisées, la daïdzéine est convertie en équol, par environ 25 à $30 \%$ des hommes et des femmes (en Occident). En effet, la production d'équol dépend de la flore intestinale caractéristique de chaque personne. S'interroger sur la possibilité d'extrapoler les résultats observés chez le rongeur à l'Homme est donc tout à fait pertinent.

Soukup et al. (2016) ont d'ailleurs récemment confirmé des différences importantes quant au métabolisme des isoflavones par le rat, la souris et l'Homme. Chez le rat et la souris, ils ont de plus montré des différences liées au sexe. Chez l'Homme et le rat, la proportion d'isoflavones aglycones 
Tableau 5. Teneurs indicatives en isoflavones aglycones d'aliments fabriqués à partir de graines entières de soja (données SOJAXA).

\begin{tabular}{lcc}
\hline & Produits au soja & Teneurs en isoflavones aglycones \\
\hline Petit Déjeuner & 1 bol de boisson au soja $(250 \mathrm{ml})$ & $33 \mathrm{mg}$ \\
Déjeuner & 1 steak de soja $(100 \mathrm{~g})$ & $15 \mathrm{mg}$ \\
Dîner & 1 dessert au soja $(100 \mathrm{~g})$ & $8 \mathrm{mg}$ \\
& & Total $: 56 \mathrm{mg} /$ jour \\
\hline
\end{tabular}

était faible $(0,5-1,3 \%$ et $0,5-3,1 \%$ respectivement), tandis qu'elle était plus élevée chez la souris (3,1-26\%), en particulier concernant la daïdzéine. À la différence de l'Homme, tous les rats et les souris se sont montrés producteurs d'équol, quel que soit leur sexe. Les auteurs, comme d'autres auparavant $(\mathrm{Gu}, 2006$; Setchell, 2011) concluent à des différences importantes entre l'Homme, le rat et la souris, pour le métabolisme des isoflavones et recommandent que ces différences soient prises en compte quand il s'agit d'extrapoler à l'Homme des résultats obtenus chez le rat ou la souris.

Par ailleurs, l'Afssa avait indiqué en 2005 que les études de toxicité par administration unique ou réitérée (le plus souvent avec la génistéine), n'ont pas mis en évidence de toxicité particulière et qu'on ne peut remettre en cause l'absence d'effets délétères spécifiques rapportés. Toutefois, l'Afssa avait estimé que la consommation traditionnelle du soja dans les populations asiatiques ne peut, à elle seule, servir de garantie à la sécurité des phyto-estrogènes et, en appliquant un facteur de sécurité de 100 à la NOAEL disponible pour la génistéine (120 mg par kg de poids corporel et jour), proposait un apport quotidien de $1 \mathrm{mg}$ d'isoflavones aglycones par kg de poids corporel et par jour, comme dose sans effet indésirable.

Plus récemment, l'Efsa (autorité européenne de sécurité alimentaire) a également évalué la sécurité des isoflavones consommées sous forme de compléments alimentaires, chez la femme ménopausée, et a conclu à la sécurité de quantités atteignant $150 \mathrm{mg}$ par jour d'isoflavones pendant de longues périodes (Efsa, 2015).

\subsection{Teneurs en isoflavones dans les graines de soja et dans les aliments au soja}

Les procédés de fabrication des produits de la SOJAXA respectent la composition initiale de la graine, et lui conservent sa richesse nutritionnelle (protéines, acides gras insaturés, absence de lactose et de cholestérol). Au niveau de la graine de soja, la teneur en isoflavones est très variable, influencée par de nombreux facteurs tels que le cultivar, les conditions d'ensoleillement, le moment de la récolte, le degré de maturité...Par exemple, selon les tables de composition américaines (USDA, 2008), la teneur en isoflavones des graines peut varier de 86 à $179 \mathrm{mg} / 100 \mathrm{~g}$. Le rapport COT (2003) rapporte des valeurs similaires, de 14 à 153 mg d'isoflavones totales/100 g de graines de soja. On considère généralement que, au niveau de la graine de soja, on trouve environ 2 à $4 \mathrm{mg}$ d'isoflavones par gramme de protéine.

Au cours de la fabrication des produits issus de la graine, les isoflavones sont en partie éliminées, jusqu'à $90 \%$ selon les procédés et les produits (Wang, 1996). Au niveau des aliments à base de soja, on trouve 1 à $3 \mathrm{mg}$ d'isoflavones par gramme de protéine (Afssa, 2005).

\subsection{Les aliments au soja et l'apport quotidien proposé par l'Afssa}

L'apport quotidien proposé par l'Afssa correspond, pour une personne de $60 \mathrm{~kg}$ par exemple, à la consommation de $60 \mathrm{mg}$ d'isoflavones aglycones par jour. Et ce, tous les jours de l'année. Concrètement, si l'on établit la liste des aliments et boissons au soja qu'il faudrait consommer pour atteindre une telle dose, on obtient les résultats présentés dans le tableau 5.

Cette simulation a été réalisée avec des valeurs moyennes, obtenues par analyses HPLC, réalisées par des laboratoires indépendants des entreprises adhérentes de la Sojaxa. On voit donc que l'apport quotidien de $1 \mathrm{mg}$ d'isoflavones par $\mathrm{kg}$ de poids corporel et par jour, tel que proposé par l'Afssa, est très supérieur aux niveaux d'apport par l'alimentation. Il faudrait consommer plus de 3 produits au soja chaque jour pour atteindre ce niveau, or ce niveau de consommation reste éloigné des pratiques actuelles des consommateurs, comme en attestent les données présentées dans la première partie de l'article.

Lors de la publication de son rapport, en 2005, l'Afssa avait jugé préférable de recommander de limiter la consommation d'isoflavones chez le nourrisson et le jeune enfant (moins de 3 ans). En effet, malgré un recul de consommation plusieurs fois millénaire en Asie, peu d'études avaient été réalisées en Occident. Ces dix dernières années, plusieurs études ont été réalisées, elles viennent apporter des données nouvelles et rassurantes quant à la sécurité des isoflavones chez le jeune enfant puis aux âges ultérieurs.

\section{Sécurité des isoflavones du soja au cours du développement}

Quand c'est possible, l'idéal pour l'alimentation d'un nourrisson est bien sûr le lait de sa mère. Ceci étant dit, l'alimentation des enfants à base de soja existe depuis des millénaires en Orient. En Occident, la première préparation destinée aux nourrissons date du début du $20^{\mathrm{e}}$ siècle (Ruhrah, 1909) et son utilisation chez les nourrissons intolérants au lait de vache date de 1929 (American Academy of Pediatrics, 1998). Ces préparations à partir de farine de soja avaient une couleur et une odeur très particulières et provoquaient souvent diarrhée et ballonnement. L'isolement des protéines de soja dès 1960 , en éliminant notamment les fibres et oligosaccharides fermentescibles, a fait disparaître ces inconvénients.

Les préparations infantiles à base de protéines de soja (PPS) existent depuis 50 ans aux États-Unis, où elles sont largement utilisées (25\% des nourrissons) en raison de leur composition exempte de lactose. En effet, la diversité des populations est telle que le nombre d'individus dépourvus de 
lactase est très important. Ce recul de 50 ans, avec des millions de nourrissons alimentés par des PPS (dont plusieurs millions sont aujourd'hui eux-mêmes parents), ont montré que les PPS permettent une croissance et un développement neuroendocrinien équivalents à ceux observés chez les nourrissons nourris avec des préparations à base de protéines de lait de vache ou avec le lait maternel.

Selon le rapport de l'Afssa de 2005, « de nombreux travaux expérimentaux montrent que les phyto-oestrogènes ont des effets sur le développement et le fonctionnement neuroendocrinien et immunitaire dans différentes espèces animales. Cependant, malgré la forte exposition et les concentrations plasmatiques rapportées chez des nourrissons alimentés de façon prolongée avec des PPS, il n'a pas été observé jusqu'à présent de troubles particuliers de la croissance et du développement endocrinien. Toutefois, on ne dispose pas d'études à long terme portant notamment sur la fertilité. Compte tenu de l'état actuel des connaissances et des incertitudes concernant les effets à long terme des fortes doses d'isoflavones ingérées de façon prolongée par des nourrissons (dans le cas où les PPS sont utilisées par leur alimentation à défaut d'allaitement maternel ou de lait de vache), il parait prudent de ne pas recommander pour la tranche d'âge de la naissance à 3 ans l'utilisation de PPS si celles-ci ne sont pas à teneur réduite en isoflavones ».

Depuis la publication de ce rapport, différentes études ont été menées afin de combler ce manque de données. Vandenplas et collaborateurs (2014) ont analysé les résultats de 35 études disponibles et concluent à l'absence de différence entre des enfants nourris avec des formules infantiles à base de protéines de soja et ceux des enfants nourris avec des formules infantiles à base de protéines de lait de vache ou au lait maternel, sur 31 paramètres relatifs à la croissance, la santé osseuse et aux fonctions métaboliques, reproductives, endocrines, immunitaires et neurologiques.

Dans le cadre de l'étude de cohorte Beginnings, l'équipe du Professeur Thomas Badger a pu comparer 101 enfants suivis depuis leur naissance jusqu'à l'âge de 5 ans (Andres, 2015). Quand ils étaient nourrissons, ces enfants avaient été nourris soit avec des préparations infantiles à base de lait de vache, soit avec des préparations infantiles à base de soja, soit au lait maternel. Les auteurs ont comparé la taille des organes reproducteurs (développement de la poitrine, de l'utérus, des ovaires chez les filles; de la prostate et des testicules chez les garçons). Aucune différence n'a été observée entre les trois types d'alimentation, ni chez les filles, ni chez les garçons. Les auteurs concluent qu' on ne trouve aucun effet du type d'alimentation sur le volume et les caractéristiques structurales des organes reproducteurs de l'enfant.

Qu'en est-il du développement ultérieur? La puberté tend à survenir plus tôt qu'auparavant (Biro, 2010; Euling, 2008). Diverses études ont eu pour objectif de comprendre l'impact des facteurs environnementaux, dont l'alimentation, sur ce phénomène. De nombreux facteurs liés à l'alimentation semblent contribuer à cette tendance, dont l'augmentation de l'adiposité. Des études épidémiologiques ont montré que la consommation de protéines et la consommation de protéines animales sont associées à une puberté plus précoce (Gunther, 2010 ; Rogers, 2010).
Du fait de leur effet potentiellement oestrogénique, les isoflavones du soja n'échappent pas aux travaux de recherche dans ce domaine : une étude transversale menée aux ÉtatsUnis, concernant 339 filles de 12 à 18 ans (appartenant à la communauté des Adventistes du $7^{\mathrm{e}}$ jour, une communauté végétarienne consommant régulièrement des aliments au soja) a montré que la consommation de soja n'était pas liée à l'âge de survenue des premières règles (12,5 ans en moyenne dans cette étude). La consommation moyenne d'aliments au soja chez ces adolescentes était de 12,9 portions par semaine (Segovia, 2014).

Diverses études menées chez l'animal ont suggéré dans le passé que la consommation d'isoflavones pourrait avoir un impact défavorable sur la fertilité (Lundh, 1990; Setchell, 1987). Il a été montré ultérieurement que ce problème était lié à une consommation excessive (Urpi, 2008) et qu'il existe des différences très marquées entre les animaux et les humains quant au métabolisme des isoflavones (Redmon, 2015 ; Rowland, 2000, 2003 ; Setchell, 2002).

À l'âge adulte, chez la femme, la consommation d'aliments au soja augmente légèrement la durée du cycle menstruel, mais n'empêche pas l'ovulation (Hooper, 2009). Une durée plus longue du cycle menstruel est considérée comme un facteur protecteur vis-à-vis du risque de cancer du sein.

Chez l'homme adulte, une revue de la littérature et une méta-analyse portant sur 32 études cliniques a montré que le soja et les isoflavones n'influencent pas les taux de testostérone, de SHBG (sex hormone binding globulin), de testostérone libre, ni l'index FAI (free androgen index) (HamiltonReeves, 2010).

Par ailleurs, après une première étude pilote suggérant une diminution de la concentration spermatique liée à la consommation de soja (Chavarro, 2008), la même équipe de recherche a récemment publié une étude transversale montrant que la consommation de soja n'est pas liée au taux de fécondation, d'implantation embryonnaire, de grossesses et de naissances (Minguez, 2015). Deux études d'intervention viennent renforcer ces données d'observation, en montrant que la consommation d'isoflavones de soja n'a pas d'effet sur la santé reproductive masculine (Beaton, 2010; Mitchell, 2001).

Selon le rapport de l'Afssa de 2005, des études menées chez l'animal suggéraient que la consommation d'isoflavones de soja pourrait augmenter le risque de récidive de cancer du sein. Le chapitre suivant s'intéresse aux études récentes menées dans le cadre de la prévention du cancer du sein ou après le diagnostic.

\section{Les aliments au soja et le cancer du sein}

\subsection{En prévention}

Dans son rapport de 2005, l'Afssa reconnaissait que la consommation de soja réduit le risque de cancer du sein de façon significative, chez les femmes asiatiques. Cette réduction du risque s'observe pour un apport de 30 à $40 \mathrm{mg}$ d'isoflavones par jour, dès l'adolescence, dans un contexte alimentaire favorable (apport important de produits végétaux, d'acides gras de la série oméga-3, apport faible de lipides saturés). Cet effet protecteur n'était pas confirmé chez la femme occidentale, 
pour laquelle l'Afssa concluait néanmoins que la consommation d'aliments au soja n'augmente pas le risque de survenue du cancer du sein.

L'incidence des cancers du sein, mais aussi celle des cancers de la prostate et du côlon, ont été reconnues plus basses en Chine, au Japon et quelques autres pays asiatiques, qu'en Amérique du Nord et en Europe (Parkin et al., 1997). Les études de migration montrent que les facteurs environnementaux expliqueraient en grande partie ces différences (Bray, 2004; Stanford, 1995). Les femmes d'origine asiatique nées aux États-Unis ont un risque de cancer du sein $60 \%$ plus élevé que les femmes d'origine asiatique nées en Asie (Ziegler, 1993).

Parmi les facteurs environnementaux, les facteurs alimentaires peuvent contribuer à cet effet protecteur : une différence majeure entre l'alimentation asiatique et l'alimentation occidentale porte sur la consommation d'aliments au soja, mais l'alimentation asiatique traditionnelle est également caractérisée par sa richesse en fibres alimentaires, sa pauvreté en graisses saturées et sa richesse en acides gras poly-insaturés.

Plusieurs études cas-témoins confirment le lien entre la consommation de soja et la protection vis-à-vis du cancer du sein dans les populations asiatiques. En particulier, on observe une diminution de $50 \%$ du risque de survenue du cancer du sein chez les femmes ayant consommé des isoflavones $(30 \mathrm{mg} /$ jour $)$ dès l'adolescence, et ayant poursuivi cette consommation tout au long de la vie (Shu, 2001). Une étude prospective réalisée chez des femmes japonaises (Yamamoto, 2003) montre une réduction de risque significative pour les plus fortes consommations d'isoflavones. Les études menées sur des populations asiatiques montrent que l'effet protecteur de la consommation d'aliments au soja est d'autant plus important que celle-ci est consommée tôt dans la vie, dès l'enfance ou au moins à partir de l'adolescence (Korde, 2009 ; Lee, 2009; Shu, 2001; Wu, 2002, 2008).

Sur la base des données épidémiologiques, l'Afssa avait conclu en 2005 à l'effet protecteur des isoflavones vis-à-vis $\mathrm{du}$ risque de survenue du cancer du sein chez les femmes asiatiques. Chez les femmes occidentales, elle avait conclu à l'absence d'effet, les apports alimentaires en isoflavones étant beaucoup plus faibles que chez les femmes asiatiques.

Une méta-analyse d'études épidémiologiques prospectives a montré que la consommation d'isoflavones de soja est liée à une diminution du risque de cancer du sein chez les femmes asiatiques, mais pas chez les populations occidentales (Dong et Qin, 2011). Par contre, il est aussi intéressant de noter que les résultats publiés dans le cadre de l'étude EPIC (étude prospective européenne sur le cancer et la nutrition) ont montré que la consommation de soja n'a pas d'incidence sur le risque de cancer du sein (Travis, 2008) : cette étude a été menée sur plus de 37000 femmes britanniques. La consommation de soja était relativement élevée et comparable à celle des Asiatiques. Cette divergence entre les résultats de cette étude et celle de Wu (2008) peut s'expliquer par le fait que c'est la consommation de soja dès l'enfance qui a l'effet le plus protecteur, chez les femmes asiatiques. Les femmes asiatiques adultes consommant beaucoup de soja ont commencé à en consommer dès l'enfance. Alors que les femmes occidentales de l'étude EPIC n'ont commencé à en consommer qu'à l'âge adulte, lors de l'adoption d'un régime végétarien.

Très récemment, l'Autorité européenne de sécurité des aliments (EFSA) a réalisé une revue systématique de la littérature pour évaluer l'existence d'une association entre la consommation d'isoflavones par les compléments alimentaires et des effets défavorables sur 3 organes clés (sein, utérus, thyroïde), chez la femme en période de ménopause. Elle conclut que «les données humaines ne supportent pas l'hypothèse d'un risque accru de cancer du sein, sur la base des études d'observation, ni un effet sur la densité mammographique ou le marqueur de prolifération Ki-67 sur la base des études d'intervention. On n'observe aucun effet sur l'épaisseur endométriale ni de changement histopathologique au niveau de l'utérus jusqu'à 30 mois de supplémentation avec $150 \mathrm{mg}$ d'isoflavones par jour. Après 60 mois, quelques changements histopathologiques bénins sont rapportés. Les taux d'hormones thyroïdiennes ne sont pas modifiés par la consommation de compléments alimentaires à base d'isoflavones » (EFSA, 2015)

\subsection{En cas d'antécédents de cancer du sein}

Selon le rapport de l'Afssa, des études menées chez l'animal suggéraient que l'exposition aux phyto-estrogènes pourrait favoriser la prolifération et la croissance tumorale, chez les femmes ménopausées avec antécédent de cancer du sein. Aussi l'Afssa recommandait-elle de ne pas dépasser l'apport quotidien de $1 \mathrm{mg}$ d'isoflavones par $\mathrm{kg}$ de poids corporel et par jour chez les femmes ayant eu un cancer du sein. À noter que cette recommandation de l'Afssa concernait plutôt les femmes ménopausées ayant recours à la supplémentation par des concentrés d'isoflavones, puisqu'on a vu qu'une alimentation intégrant habituellement des aliments au soja ne permet pas d'atteindre l'apport quotidien proposé par l'Afssa.

De récentes études ont montré que ni les protéines de soja, ni les aliments au soja, ni les compléments alimentaires d'isoflavones n'ont d' effet sur des marqueurs du risque de cancer du sein comme la densité mammographique (Hooper, 2010; Wu, 2015) ou la prolifération des cellules mammaires (Khan et al., 2012 ; Palomares, 2004 ; Sartippour, 2004 ; Shike, 2014).

De même, les études d'intervention, contrairement aux études menées chez l'animal, suggèrent que les isoflavones n'entraînent pas de risque chez les patientes atteintes d'un cancer du sein : les produits au soja n'augmentent pas la prolifération de cellules mammaires pour les femmes ayant subi une biopsie avant et après exposition aux isoflavones (Messina et Wood, 2008; Khan et al., 2012).

Enfin, les études épidémiologiques disponibles aujourd'hui indiquent que non seulement les aliments à base de soja n'aggravent pas le pronostic des patientes atteintes d'un cancer du sein, mais que la consommation de soja après le diagnostic de cancer peut même améliorer le pronostic des patientes. En effet, une méta-analyse de 5 études prospectives (deux études aux États-Unis (Caan, 2011; Guha, 2009) et 3 études en Chine (Kang, 2010; Shu, 2009; Zhang, 2012), incluant plus de 11000 femmes ayant un cancer du sein suivies pendant des périodes allant de 4 à plus de 7 ans, a montré que la consommation de soja après le diagnostic de leur maladie était 
associée significativement à une diminution de la récidive de cancer et de la mortalité (Chi, 2013). Dans l'étude menée à Shanghai sur plus de 5000 patientes suivies pendant près de 4 ans, les femmes du quatrième quartile de consommation de protéines de soja $(<15,3 \mathrm{~g} / \mathrm{jour})$, avaient un taux de décès et de récurrence de la maladie inférieur d'environ $30 \%$ par rapport aux consommations les plus faibles $(\leqslant 5,3 \mathrm{~g} / \mathrm{jour}$ ) (Shu, 2009). Dans cette étude, la consommation de soja exerçait son effet protecteur pour les femmes pré- et post-ménopausées. La méta-analyse de Nechuta (2012) a établi qu'une consommation d'isoflavones supérieure à $10 \mathrm{mg}$ par jour, après un diagnostic de cancer du sein, est associée à une diminution de $25 \%$ du risque de récidive du cancer du sein.

Il est important de noter que l'effet protecteur de la consommation de soja est observé aussi bien pour les femmes asiatiques que pour les femmes non asiatiques (Nechuta, 2012). Deux études ont été réalisées aux États-Unis avec principalement des femmes de type caucasien : l'étude WHEL (Women's Healthy Eating and Living, Caan, 2011), incluant près de 3000 patientes et l'étude LACE, sur près de 2000 patientes (Guha, 2009). Dans ces deux études, une consommation importante de soja a été associée à une amélioration du pronostic des patientes.

En outre, alors que les études menées chez l'animal suggéraient un effet défavorable des isoflavones du soja sur l'efficacité des traitements anti-cancéreux comme le tamoxifène, les données épidémiologiques récentes suggèrent plutôt une amélioration de l'effet de ces traitements (Guha, 2009; Nechuta, 2012; Kang, 2010).

Ces données récentes ont amené l'American Cancer Society (Rock et al., 2012) et l'American Institute for Cancer Research (2012) à actualiser leurs positions : selon ces deux institutions, les aliments au soja peuvent ainsi être consommés par les femmes ayant un cancer du sein. Enfin, le Fonds international de recherche sur le cancer (World Cancer Research Fund International, 2014) a récemment conclu à l'existence d'un lien possible entre la consommation d'aliments au soja et un meilleur pronostic après cancer du sein.

Dans son rapport de 2005, l'Afssa reconnaissait l'intérêt des protéines de soja vis-à-vis du taux de LDL-cholestérol circulant, facteur de risque cardiovasculaire reconnu. Le chapitre suivant fait le point sur les données scientifiques récentes relatives au lien entre soja et santé cardiovasculaire.

\section{Les aliments au soja et la santé cardiovasculaire}

Un mode de vie sain réduit le risque de maladie cardiovasculaire : le tabagisme, l'obésité, l'inactivité physique et une alimentation déséquilibrée sont des facteurs de risque de maladie cardiovasculaire. Même si l'alimentation seule ne suffit pas à réduire le risque, une grande consommation de fruits et légumes, une consommation réduite de sel et le remplacement des graisses saturées par des graisses insaturées constituent des mesures recommandées dans le cadre de la prévention des maladies cardiovasculaires.

Les études épidémiologiques indiquent que l'incidence des maladies cardiovasculaires est 4 fois plus basse dans les pays asiatiques où la consommation de produits de soja est élevée, que dans les pays occidentaux où elle est faible (Demonty, 2003). Du fait de leur faible teneur en graisses saturées et de leur richesse en acides gras insaturés, les aliments au soja peuvent trouver leur place dans une alimentation favorable à la santé cardiovasculaire. En outre, divers composants du soja peuvent également jouer un rôle dans cet effet favorable du soja sur les fonctions cardiovasculaires.

Dans son rapport de 2005, l'Afssa concluait à l'intérêt de consommer des protéines de soja pour abaisser le taux circulant de cholestérol ( $30 \mathrm{~g}$ par jour), et concluait que les isoflavones de soja n'ont pas d'effet sur le cholestérol circulant, mais un effet favorable sur la vasotonicité (à partir d'un apport de $45 \mathrm{mg}$ par jour).

Les protéines du soja exercent un effet hypocholestérolémiant connu depuis 1967. Sur des sujets ayant un cholestérol élevé, initialement supérieur à 2,20 g/L, la consommation de $25 \mathrm{~g}$ de protéines de soja par jour entraîne une baisse du cholestérol (Bakhit, 1994). Celle-ci est d'autant plus élevée que le cholestérol est initialement haut, ainsi que l'a confirmé la méta-analyse de 38 études réalisée en 1995 par Anderson.

Les résultats de cette méta-analyse ont conduit la FDA à autoriser en 1999 une allégation santé reliant la consommation de $25 \mathrm{~g}$ de protéines de soja par jour et un abaissement de la cholestérolémie, dans le cadre d'une alimentation pauvre en cholestérol, en lipides et en graisses saturées. Depuis, une dizaine de pays ont adopté cette allégation de santé, dont le Canada en 2014 (Benkhedda, 2014), alors que l'EFSA, de son côté, a considéré que le niveau de preuve n'était pas suffisant (EFSA, 2012). De nombreux essais cliniques ont utilisé des quantités de $25 \mathrm{~g}$ de protéines de soja ou plus, mais des données suggèrent que des quantités plus faibles sont également efficaces (Hardland et Haffner, 2008). Le mécanisme par lequel le LDL-cholestérol est diminué n'a pas été définitivement identifié, bien que certains travaux suggèrent que des peptides formés lors de la digestion de la protéine de soja stimuleraient les récepteurs hépatiques au LDL (Lami, 2015; Lovati, 2000).

Selon la méta-analyse réalisée par Reynolds (2006), la consommation de protéine de soja permet de réduire le taux de LDL-cholestérol de 4,2 \%, ce qui concorde avec plusieurs autres méta-analyses montrant que la consommation de protéine de soja permet une réduction de 4 à $6 \%$ du LDLcholestérol (Anderson et Bush, 2011; Harland et Haffner, 2008; Weggemans et Trautwein, 2003; Zhan et Ho, 2005). Cette réduction est pertinente pour la santé, puisqu'on estime que réduire le taux de LDL-cholestérol de $1 \%$ correspond à une réduction du risque de maladie cardiovasculaire de 1 à $2 \%$ (Charland et Malone, 2010).

Outre les effets des protéines de soja sur le LDLcholestérol, les méta-analyses montrent également des effets plus modestes sur le taux de triglycérides et sur le taux de HDL-cholestérol (Anderson, 2011; Harland, 2008; Reynolds, 2006; Weggemans et Trautwein, 2003 ; Zhan et Ho, 2005).

Les aliments au soja font partie du régime portfolio proposé par l'équipe de Jenkins, dont les études ont montré une réduction de $30 \%$ du taux de LDL-cholestérol sous l'effet de cette alimentation pauvre en graisses saturées, riche en fruits et légumes et apportant des noix et des aliments au soja riches en protéines végétales (Jenkins, 2002, 2003, 2007, 2015 ; Ramprasath, 2014). 
Outre les effets du soja sur le taux de LDL-cholestérol, plusieurs méta-analyses ont conclu à un effet sur la tension artérielle d'environ $2,5 \mathrm{mmHg}$ pour la tension diastolique et $1,5 \mathrm{mmHg}$ pour la tension systolique respectivement, entrầnant une réduction du risque d'accident vasculaire cérébral de $10 \%$, de maladie cardiovasculaire de $5 \%$ et de mortalité globale de $4 \%$ (Dong et Qin, 2011; Hooper, 2008; Liu, 2012; Taku, 2010). Cependant, dans plusieurs des études analysées, la tension artérielle était un critère d'évaluation secondaire. Des études supplémentaires, avec la tension artérielle comme critère principal, seront donc nécessaires avant de conclure quant à l'effet anti-hypertenseur de la protéine de soja.

On dispose par contre de preuves conséquentes quant à l'effet favorable des isoflavones de soja sur la fonction endothéliale. Celle-ci est considérée comme un indicateur du risque de maladie cardiovasculaire, car les cellules endothéliales jouent un rôle important dans l'inhibition du développement de l'artériosclérose. Une méta-analyse récente (Beavers, 2012) a montré que les isoflavones de soja (doses allant de 50 à $100 \mathrm{mg}$ par jour) amélioraient considérablement la fonction endothéliale chez les femmes ménopausées.

Les lipides du soja sont pauvres en graisses saturées et riches en acides gras polyinsaturés de la famille oméga-6 et de la famille oméga 3 (acide alpha-linolénique). De très nombreuses études cliniques et épidémiologiques ont montré l'intérêt de cet acide gras en prévention cardiovasculaire, notamment en prévention secondaire, en particulier du fait de son effet antiagrégant plaquettaire et anti-arythmique (Lecerf, 2002). Par ailleurs, l'Autorité européenne de sécurité des aliments (EFSA) a conclu à l'intérêt de réduire la consommation de graisses saturées pour maintenir un taux circulant normal de LDL-cholestérol (EFSA, 2011).

Au total, ces données indiquent qu'il est judicieux d'introduire des aliments à base de soja dans une alimentation visant à réduire le risque de maladie cardiovasculaire. Les aliments au soja apportent une protéine de haute qualité, un profil d'acides gras favorable (pauvre en graisses saturées et riches en graisses insaturées, dont les acides gras poly-insaturés oméga-6 et oméga-3) et n'apportent pas de cholestérol. Ce sont les différents composants du soja qui, ensemble, dans leur matrice végétale d'origine, peuvent produire des effets positifs.

\section{Conclusion}

Les effets des aliments au soja sur la santé sont étudiés depuis plus de 25 ans, plus de 2000 publications scientifiques leur étant consacrées chaque année.

Malgré une consommation plusieurs fois millénaire en Asie, ils sont aujourd'hui consommés en quantités modestes en Europe. Les 6 Français sur 10 qui ne consomment pas de soja aujourd'hui sont en attente d'informations sur l'origine géographique du soja, sur les modes de production des aliments élaborés à partir de la graine de soja, sur leurs utilisations culinaires et leurs avantages nutritionnels notamment.

Pourtant, les aliments au soja présentent des qualités nutritionnelles reconnues : dans le contexte actuel où l'alimentation occidentale typique conduit le plus souvent à des apports excessifs en lipides et en graisses saturées, introduire des aliments au soja dans l'alimentation permet de ré-équilibrer le profil des acides gras de l'alimentation (en réduisant l'apport en graisses saturées et en augmentant l'apport en acides gras poly-insaturés), tout en garantissant l'apport de protéines de haute qualité nutritionnelle, mais aussi de fibres, de vitamines et de minéraux. Ces atouts nutritionnels justifient pleinement leur place au sein d'une alimentation diversifiée, contribuant à l'équilibre alimentaire et à la santé.

Les études scientifiques récentes permettent également de conclure à la sécurité des aliments au soja au cours du développement et vis-à-vis du risque de cancer du sein, certaines études suggérant même que l'effet protecteur des aliments au soja, observé chez les femmes asiatiques, pourrait aussi être présent chez les femmes occidentales.

Enfin, l'introduction d'aliments au soja dans l'alimentation quotidienne permet aussi de contribuer à la santé cardiovasculaire.

\section{Déclaration des conflits d'intérêt}

Les auteurs de cet article, membres de la Commission Scientifique et Réglementaire de la Sojaxa, sont tous salariés des entreprises adhérentes à la Sojaxa : Alpro, LSDH, Nutrition \& Nature, Triballat Noyal.

\section{Références}

AFSSA (Agence française de sécurité sanitaire des aliments). 2005. Sécurité et bénéfices des phyto-estrogènes apportés par l'alimentation - Recommandations. Rapport mars 2005. Disponible sur : http://www.afssa.fr/Documents/NUT-Ra-Phytoestrogenes.pdf

American Academy of Pediatrics. 1998. Soy Protein-based Formulas; recommendations for use in infant feeding. Pediatrics 101: 148-153.

American Institute for Cancer Research. 2012. Soy is safe for breast cancer survivors. Disponible sur : www.aicr.org/ cancer-research-update/2012/november_21_2012/cru-soy-safe. html

Anderson JW, Hohnstone BM, Cokk-Neweil ME. 1995. Metaanalysis of the effects of soy protein intake on serum lipids. New Engl. J. Med. 333: 276-382.

Anderson JW, Bush HM. 2011. Soy protein effectson serum lipoproteins: a quality assessment and meta-analysis of randomized, controlled studies. J. Am. Coll. Nutr. 30: 79-91.

Andres A, Moore MB, Linam LE, et al. 2015. Compared with feeding infants breast milk or cow-milk formula, soy formula feeding does not affect subsequent reproductive organ size at 5 years of age. J. Nutr. 145: 871-875.

Bakhit RM, Klein BP, Essex-Sorlie D, et al. 1994. Intake of $25 \mathrm{~g}$ of soybean protein with or without soybean fiber alters plasma lipids in men with elevated cholesterol concentrations. J. Nutr. 124: 213-222.

Beaton LK, McVeigh BL, Dillingham BL, Lampe JW, Duncan AM. 2010. Soy protein isolates of varying isoflavone content do not adversely affect semen quality in healthy young men. Fertil. Steril. 94: 1717-1722.

Beavers DP, Beavers KM, Miller M, et al. 2012. Exposure to isoflavone-containing soy products and endothelial function : a Bayesian meta-analysis of randomized controlled trials. Nutr. Metab. Cardiovasc. Dis. 22: 182-191. 
Benkhedda KB, B, Sinclair SE, Marles RJ, et al. 2014. Food Risk Analysis Communication. Issued By Health Canada's Food Directorate. Health Canada's Proposal to Accept a Health Claim about Soy Products and Cholesterol Lowering. Int. Food. Risk Anal. J. 4: 22.

Biro FM, Galvez MP, Greenspan LC, et al. 2010. Pubertal Assessment Method and Baseline Characteristics in a Mixed Longitudinal Study of Girls. Pediatrics.

Bray F, Mc Carron P, Parkin DM. 2004. The changing global patterns of female breast cancer incidence and mortality. Breast. Cancer Res. 6: 229-239.

Caan BJ, Natarajan L, Parker B, et al. 2011. Soy food consumption and breast cancer prognosis. Cancer Epidemiol. Biomark. Prev. 20: 854-858.

Charland SL, Malone DC. 2010. Prediction of cardiovascular event risk reduction from lipid changes associated with high potency dyslipidemia therapy. Curr. Med. Res. Opin. 26: 365-375.

Chavarro JE, Toth TL, Sadio SM, Hauser R. 2008. Soy food and isoflavone intake in relation to semen quality parameters among men from an infertility clinic. Hum. Reprod. 23: 2584-2590.

Chi F, Wu R, Zeng YC, Xing R, Liu Y, Xu ZG. 2013. Post-diagnosis soy food intake and breast cancer survival : A meta-analysis of cohort studies. Asian Pac. J. Cancer Prev. 14: 2407-2412.

COT. 2003. Committee on Toxicity of Chemicals in Food, Consumer Products and the Environment. Phytoestrogens and Health. May 2003, rapport disponible sur le site Internet de la FSAUK. Disponible sur : http://cot.food.gov.uk/sites/default/files/cot/ phytoreport0503.pdf

Demonty I, Lamarche B, Peter J.H, Jones PD. 2003. Role of isoflavones in the hypocholesterolemic effect of soy. Nutr. Rev. 61: 189-203.

Dong JY, Qin LQ. 2011. Soy isoflavones consumption and risk of breast cancer incidence or recurrence : a meta-analysis of prospective studies. Breast. Cancer Res. Treat. 125: 315-323.

Dong JY, Tong X, Wu ZW, et al. 2011. Effect of a soya protein on blood pressure : a meta-analysis of randomised controlled trials. Br. J. Nutr. 106: 1-10.

EFSA Panel on Dietetic Products, Nutrition, and Allergies (NDA). 2010. Scientific Opinion on Dietary Reference Values for carbohydrates and dietary fibre. EFSA J. 8: 1462.

EFSA Panel on Dietetic Products, Nutrition, and Allergies (NDA). 2011. Scientific Opinion on the substantiation of health claims related to the replacement of mixtures of saturated fatty acids (SFAs) as present in foods or diets with mixtures of monounsaturated fatty acids (MUFAs) and/or mixtures of polyunsaturated fatty acids (PUFAs), and maintenance of normal blood LDL-cholesterol concentrations pursuant to Article 13(1) of Regulation (EC) No 1924/2006. EFSA J. 9: 2069.

EFSA Panel on Dietetic Products, Nutrition, and Allergies (NDA). 2012. Scientific Opinion on the substantiation of a health claim related to isolated soy protein and reduction of blood LDLcholesterol concentrations pursuant to Article 14 of Regulation (EC) No 1924/2006. EFSA J. 10: 2555.

EFSA Panel on Food Additives and Nutrient Sources added to Food (ANS). 2015. Risk assessment for peri- and post-menopausal women taking food supplements containing isolated isoflavones. EFSA J. 13: 4246.

Euling SY, Herman-Giddens ME, Lee PA, et al. 2008. Examination of US puberty-timing data from 1940 to 1994 for secular trends : panel findings. Pediatrics 121 : S172-S191.

FAO (Food and Agriculture Organization of the United Nations), 2013. Dietary protein quality evaluation in human nutrition. Report of an FAO Expert Consultation. FAO Food and Nutrition Paper 92, Rome, 2013.
FDA. 1999. Food Labeling: Health Claims; Soy Protein and Coronary Heart Disease. In : Federal Register, 1999, Vol. 64, No. 206, 57699-57733.

Gilani GS, Cockell KA, Sepehr E. 2005. Effects of antinutritional factors on protein digestibility and amino acid availability in foods. J. AOAC Int. 88: 967-87.

Guha N, Kwan ML, Quessenberry CP Jr, et al. 2009. Soy isoflavones and risk of cancer recurrence in a cohort of breast cancer survivors : the Life After Cancer Epidemiology study. Breast. Cancer Res. Treat. 118: 395-405.

Gu L, House SE, Prior RL, et al. 2006. Metabolic phenotypes of isoflavones differ among female rats, pigs, monkeys, and women. $J$. Nutr. 136: 1215-1221.

Gunther AL, Karaolis-Danckert N, Kroke A, Remer T, Buyken AE. 2010. Dietary protein intake throughout childhood is associated with the timing of puberty. J. Nutr. 140: 565-571.

Hamilton-Reeves JM, Vazquez G, Duval SJ, Phipps WR, Kurzer MS, Messina MJ. 2010. Clinical studies show no effects of soy protein or isoflavones on reproductive hormones in men : results of a meta-analysis. Fertil. Steril. 94: 997-1007.

Harland JI, Haffner TA. 2008. Systematic review, meta-analysis and regression of randomized controlled trials reporting an association between an intake of circa $25 \mathrm{~g}$ soya protein per day and blood cholesterol. Atherosclerosis 200: 13-27.

Heaney RP, Weaver CM, Fitzsimmons ML. 1991. Soybean phytate content : effect on calcium absorption. Am. J. Clin. Nutr. 53: 745747.

Hooper L, Kroon PA, Rimm EB, et al. 2008. Flavonoids, flavonoidrich foods, and cardiovascular risk : a meta-analysis of randomized controlled trials. Am. J. Clin. Nutr. 88: 38-50.

Hooper L, Ryder JJ, Kurzer MS, et al. 2009. Effects of soy protein and isoflavones on circulating hormone concentrations in pre- and post-menopausal women : a systematic review and meta-analysis. Hum. Reprod. Update 15: 423-440.

Hooper L, Madhavan G, Tice JA, Leinster SJ, Cassidy A. 2010. Effects of isoflavones on breast density in pre- and postmenopausal women : a systematic review and meta-analysis of randomized controlled trials. Hum. Reprod. Update 16: 745-760.

Hughes GJ, Ryan DJ, Mukherjea R, Schasteen CS. 2011. Protein digestibility-corrected amino acid scores (PDCAAS) for soy protein isolates and concentrate : Criteria for evaluation. J. Agric. Food Chem. 59: 12707-12712.

Jenkins DJ, Kendall CW, Faulkner D, et al. 2002. A dietary portfolio approach to cholesterol reduction : combined effects of plant sterols, vegetable proteins, and viscous fibers in hypercholesterolemia. Metabolism 51: 1596-604.

Jenkins DJ, Kendall CW, Marchie A et al. 2003. Effects of a dietary portfolio of cholesterol-lowering foods vs lovastatin on serum lipids and C-reactive protein. JAMA 290: 502-10.

Jenkins DJ, Josse AR, Wong JM, et al. 2007. The portfolio diet for cardiovascular risk reduction. Curr. Atherosc. Rep. 9: 501-507.

Jenkins DJ, Jones PJ, Frohlich J, et al. 2015. The effect of a dietary portfolio compared to a DASH-type diet on blood pressure. Nutr. Metab. Cardiovasc. Dis. 25: 1132-1139.

Kang X, Zhang Q, Wang S, Huang X, Jin S. 2010. Effect of soy isoflavones on breast cancer recurrence and death for patients receiving adjuvant endocrine therapy. CMAJ 182: 1857-1862.

Khan SA, Chatterton RT, Michel N, et al. 2012. Soy isoflavone supplementation for breast cancer risk reduction : A randomized phase II trial. Cancer Prev. Res. (Phila.) 5: 309-319.

Korde LA, Wu AH, Fears T, et al. 2009. Childhood soy intake and breast cancer risk in Asian American women. Cancer Epidemiol. Biomark. Prev. 18: 1050-1059. 
Kuiper GG, Carlsson B, Grandien K, et al. 1997. Comparison of the ligand binding specificity and transcript tissue distribution of estrogen receptors alpha and beta. Endocrinology 138: 863-870.

Kuiper GG, Lemmen JG, Carlsson B, et al. 1998. Interaction of estrogenic chemicals and phytoestrogens with estrogen receptor beta. Endocrinology 139: 4252-4223.

Lammi C, Zanoni C, Arnoldi A, Vistoli G. 2015. Two peptides from soy beta-conglycinin induce a hypocholesterolemic effect in HepG 2 cells by a statin-like mechanism : Comparative in vitro and in silico modeling studies. J. Agric. Food Chem. 63: 79457951.

Lecerf J.M., Borgies B. 2002. Effects of soybean oil on plama lipoproteins and cardiovascular risk of men and women. OCL 9: 96-99.

Lee SA, Shu XO, Li H, et al. 2009. Adolescent and adult soy food intake and breast cancer risk : results from the Shanghai Women's Health Study. Am. J. Clin. Nutr. 89: 1920-1926.

Liu XX, Li SH, Chen JZ et al. 2012. Effect of soy isoflavones on blood pressure : a meta-analysis of randomized controlled trials. Nutr. Metabl. Cardiovasc. Dis. 22: 463-470.

Lovati MR, Manzoni C, Gianazza E, et al. 2000. Soy protein peptides regulate cholesterol homeostasis in Hep G2 cells. J. Nutr. 130: 2543-2549.

Lundh TJ-O, Petterson HL, Martinsson KA. 1990. Comparative levels of free and conjugated plant estrogens in blood plasma of sheep and cattle fed estrogenic silage. J. Agric. Food Chem. 38: $1530-1534$.

Messina MJ, Wood CE. 2008. Soy isoflavones, estrogen therapy, and breast cancer risk : analysis and commentary. Nutr. J. 7 : 17.

Minguez-Alarcon L, Afeiche MC, Chiu YH, et al. 2015. Male soy food intake was not associated with in vitro fertilization outcomes among couples attending a fertility center. Andrology 3: 702-8.

Mitchell JH, Cawood E, Kinniburgh D, Provan A, Collins AR, Irvine DS. 2001. Effect of a phytoestrogen food supplement on reproductive health in normal males. Clin. Sci. (Lond.) 100: 613-618.

Nechuta SJ, Caan BJ, Chen WY, et al. 2012. Soy food intake after diagnosis of breast cancer and survival : an in-depth analysis of combined evidence from cohort studies of US and Chinese women. Am. J. Clin. Nutr. 96: 123-32.

Palomares MR, Hopper L, Goldstein L, Lehman CD, Storer BE, Gralow JR. 2004. Effect of soy isoflavones on breast proliferation in postmenopausal breast cancer survivors. Breast. Cancer Res. Treat. 88: 4002.

Parkin D.M., Whelan S.L., Ferlay J. 1997. Cancer incidence in five continents. Lyon (France) : by International Agency for research on Cancer, Vol. VIII.

Ramprasath VR, Jenkins DJ, Lamarche B, et al. 2014. Consumption of a dietary portfolio of cholesterol lowering foods improves blood lipids without affecting concentrations of fat soluble compounds. Nutr. J. 13: 101.

Redmon JM, Shrestha B, Cerundolo R, Court MH. 2015. Soy isoflavone metabolism in cats compared with other species : urinary metabolite concentrations and glucuronidation by liver microsomes. Xenobiotica 1-10.

Reynolds K, Chin A, Lees KA et al. 2006. A meta-analysis of the effect of soy protein supplementation on serum lipids. Am. J. Cardiol. 98: 633-40.

Rock CL, Doyle C, Demark-Wahnefried W, et al. 2012. Nutrition and physical activity guidelines for cancer survivors. CA Cancer J. Clin. 62: 242-74.

Rogers IS, Northstone K, Dunger DB, Cooper AR, Ness AR, Emmett PM. 2010. Diet throughout childhood and age at menarche in a contemporary cohort of British girls. Public Health Nutr. 1-12.
Rowland IR, Wiseman H, Sanders TA, Adlercreutz H, Bowey EA. 2000. Interindividual variation in metabolism of soy isoflavones and lignans : influence of habitual diet on equol production by the gut microflora. Nutr. Cancer. 36: 27-32.

Rowland I, Faughnan M, Hoey L, Wahala K, Williamson G, Cassidy A. 2003. Bioavailability of phyto-oestrogens. Br. J. Nutr. 89: S45S58.

Ruhrah J. 1909. The soy bean in infant feeding : preliminary report. Arch. Pediatr. 26: 496-501.

Rutherfurd SM, Fanning AC, Miller BJ, Moughan PJ. 2015. Protein digestibility-corrected amino acid scores and digestible indispensable amino acid scores differentially describe protein quality in growing male rats. J. Nutr. 145: 372-379.

Sartippour MR, Rao JY, Apple S, et al. 2004. A pilot clinical study of short-term isoflavone supplements in breast cancer patients. Nutr. Cancer. 49: 59-65.

Segovia-Siapco G, Pribis P, Messina M, Oda K, Sabate J. 2014. Is soy intake related to age at onset of menarche ? A cross-sectional study among adolescents with a wide range of soy food consumption. Nutr. J. 13: 54.

Setchell KD, Gosselin SJ, Welsh MB, et al. 1987. Dietary estrogens-a probable cause of infertility and liver disease in captive cheetahs. Gastroenterology 93: 225-233.

Setchell KD, Brown NM, Lydeking-Olsen E. 2002. The clinical importance of the metabolite equol-a clue to the effectiveness of soy and its isoflavones. J Nutr. 132: 3577-3584.

Setchell KD, Brown NM, Zhao X, et al. 2011. Soy isoflavone phase II metabolism differs between rodents and humans : implications for the effect on breast cancer risk. Am. J. Clin. Nutr. 94: 1284-94.

Shike M, Doane AS, Russo L, et al. 2014. The effects of soy supplementation on gene expression in breast cancer : a randomized placebo-controlled study. J. Natl. Cancer Inst. 106, doi :10.1093/jnci/dju189.

Shu X.O., Jin F., DaïQ., et al. 2001. Soy food intake during adolescence and subsequent risk of breast cancer among Chinese women. Cancer Epidem. Biomark. Prev. 10: 483-488.

Shu XO, Zheng Y, Cai H, et al. 2009. Soy food intake and breast cancer survival. JAMA 302: 2437-2443.

Sojaxa. 2015. Rapport d'étude Quali-Quanti «Les Français et les aliments au soja », 12 janvier 2015.

Soukup ST, Helppi J, Müller DR, et al. 2016. Phase II metabolism of the soy isoflavones genistein and daidzein in humans, rats and mice : a cross-species and sex comparison. Arch. Toxicol. 90: $1335-1347$.

Stanford J.L., Herrinton L.J., Schwartz S.M., et al. 1995. Breast cancer incidence in Asian migrants to the United States and their descendants. Epidemiology 6: 181-183.

Taku K, Lin N, Cai D et al. 2010. Effects of soy isoflavone extract supplements on blood pressure in adult humans : systematic review and meta-analysis of randomized placebo-controlled trials. J. Hypertension 28: 1971-1982.

Tang AL, Walker KZ, Wilcox G, Strauss BJ, Ashton JF, Stojanovska L. 2010. Calcium absorption in Australian osteopenic postmenopausal women : an acute comparative study of fortified soymilk to cows' milk. Asia Pac. J. Clin. Nutr. 19: 243-249.

Travis RC, Allen NE, Appleby PN, et al. 2008. A prospective study of vegetarianism and isoflavone intake in relation to breast cancer risk in British women. Int. J. Cancer 122: 705-710. 
Urpi-Sarda M, Morand C, Besson C, et al. 2008. Tissue distribution of isoflavones in ewes after consumption of red clover silage. Arch. Biochem. Biophys. 476: 205-210.

USDA (U.S. Department of Agriculture, Agricultural Research Service). 2008. USDA Database for the Isoflavone Content of Selected Foods, Release 2.0. Disponible sur : http://www.ars. usda.gov/SP2UserFiles/Place/80400525/Data/isoflav/Isoflav_ R2.pdf

USDA (US Department of Agriculture, Agricultural Research Service, Nutrient Data Laboratory). 2015. USDA National Nutrient Database for Standard Reference, Release 28. Version Current : September 2015. Disponible sur : https://ndb.nal.usda. gov/ndb/foods/show $/ 4846$ ? fgcd $=\&$ manu $=\&$ lfacet $=\&$ format $=\&$ count $=\& \max =35 \&$ offset $=\&$ sort $=\&$ qlookup $=16109$

Vandenplas Y, Gutierrez Castrellon P, Rivas R, et al. 2014. Safety of soya-based infant formulas in children. Br. J. Nutr. 111: 1340 1360.

Wang H-J, Murphy PA. 1996. Mass balance study of isoflavones during soybean processing. J. Agric. Food Chem. 44: 2377-2383.

Weggemans RM, Trautwein EA. 2003. Relation between soyassociated isoflavones and LDL and HDL cholesterol concentrations in humans : a meta-analysis. Eur. J. Clin. Nutr. 57: 940-946.

WHO. 1985. Energy and Protein Requirements : Report of a Joint FAO/WHO/UNU Expert Consultation. Geneva : WHO Technical Report Series 724.

WHO. 2007. Protein and amino acid requirements in human nutrition : Report of a Joint WHO/FAO/UNU Expert Consultation. Geneva : WHO Technical Report Series 935.
World Cancer Research Fund International. 2014. Continuous Update Project Report : Diet, Nutrition, Physical Activity, and Breast Cancer Survivors. 2014. Disponible sur : www.wcrf.org/sites/ default/files/Breast-Cancer-Survivors-2014-Report.pdf.

Wu AH, Wan P, Hankin J, Tseng CC, Yu MC, Pike MC. 2002. Adolescent and adult soy intake and risk of breast cancer in Asian-Americans. Carcinogenesis 23: 1491-1496.

Wu AH, Yu MC, Tseng CC, Pike MC. 2008. Epidemiology of soy exposures and breast cancer risk. Br. J. Cancer 98: 9-14.

Wu AH, Spicer D, Garcia A, et al. 2015. Double-blind randomized 12-month soy intervention had no effects on breast MRI fibroglandular tissue density or mammographic density. Cancer Prev. Res. (Phila) 8: 942-951.

Yamamoto S., Sobue T., Kobayashi M., et al. 2003. Soy, isoflavones and breast cancer risk in Japan. J. Natl. Cancer Inst. 95: 906-913.

Zhan S, Ho SC. 2005. Meta-analysis of the effects of soy protein containing isoflavones on the lipid profile. Am. J. Clin. Nutr. 81: 397-408.

Zhang YF, Kang HB, Li BL, Zhang RM. 2012. Positive effects of soy isoflavone food on survival of breast cancer patients in China. Asian Pac. J. Cancer. Prev. 13: 479-482.

Zhao Y, Martin BR, Weaver CM. 2005. Calcium bioavailability of calcium carbonate fortified soymilk is equivalent to cow's milk in young women. J. Nutr. 135: 2379-2382.

Ziegler RG, Hoover RN, Pike MC, et al. 1993. Migration patterns and breast cancer risk in Asian-American women. J. Natl. Cancer Inst. 85: 1819-1827.

Cite this article as: Dominique Chevalier, Christine Debeuf, Gwénaële Joubrel, Martine Kocken, Nadine Planchenault. Les aliments au soja : consommation en France, qualités nutritionnelles et données scientifiques récentes sur la santé. OCL 2016, 23(4) D405. 